NASA Technical Memorandum 107396

AIAA-97-0893

\title{
A Rocket Engine for Mars Sample Return Using In Situ Propellants
}

Diane L. Linne

Lewis Research Center

Cleveland, Ohio

Prepared for the

35th Aerospace Sciences Meeting \& Exhibit

sponsored by the American Institute of Aeronautics and Astronautics

Reno, Nevada, January 6-10, 1997

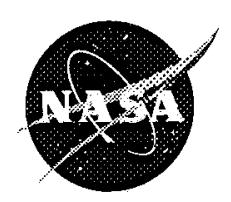

National Aeronautics and

Space Administration 


\title{
A ROCKET ENGINE FOR MARS SAMPLE RETURN USING IN SITU PROPELLANTS
}

\author{
Diane L. Linne \\ National Aeronautics and Space Administration \\ Lewis Research Center \\ Cleveland, Ohio 44135
}

\begin{abstract}
Recent studies for the planned Mars sample return mission were reviewed and modified to utilize carbon monoxide and oxygen as potential in situ propellants. Based on these studies a representative full scale engine thrust of $2225 \mathrm{~N}$ (500 lbf) was selected as appropriate to demonstrate performance, and the design for that engine is presented. Previous experimental results combined with parametric analyses were used to define the geometry for the engine which operates on liquid carbon monoxide and liquid oxygen. The engine was constructed using a combination of high-temperature alloys and lightweight ceramics. The materials selected were hafnium oxide, iridium, rhenium, and carbon-carbon.
\end{abstract}

\section{Introduction}

Current plans for the exploration of Mars include a mission to return samples from the planet to Earth. A prime factor for this mission is to minimize costs. This can be accomplished by minimizing payload size and mass, resulting in a smaller launch vehicle. Lightweight materials technologies for the tanks, vehicle structure, and engines is one method of reducing the Earth launch mass of a Mars mission. The use of in situ propellants for the return trip is another technique for keeping the Earth launch mass of a direct return mission within the desired mass envelope. The atmosphere of Mars consists of 96 percent carbon dioxide at $\sim 1 / 100$ th the pressure on Earth. This carbon dioxide can be split into oxygen and carbon monoxide, or, with some Earth-supplied hydrogen, oxygen and methane. Through the use of in situ propellants, the high mass of the return propellants can be replaced with a relatively lightweight propellant production plant. Studies have shown that the Earth launch mass for a sample return mission can be reduced by 30 to 60 percent. $^{1-4}$

Although carbon monoxide and oxygen propellants offer great advantage because they can be made entirely from the Mars atmosphere, they provide relatively low performance in a rocket engine. It is therefore desirable to maximize engine performance through experiment and analysis. Some experimental and analytical work has already been performed with the carbon monoxide and oxygen propellants. The ignition, combustion, and heat transfer characteristics have been studied in subscale rocket engine hardware. ${ }^{5-8}$ However, in the subscale tests no effort was made to optimize the engine hardware for the carbon monoxide and oxygen propellants. In a separate effort, a lightweight, passively cooled engine has been tested for small space engine applications. ${ }^{9}$ While the fabrication and materials technologies employed are promising, they need to be tested in a full scale engine with the carbon monoxide and oxygen propellants before they can be used for a sample return mission.

The results of the subscale experimental and analytical investigations into the kinetics and behavior of the combustion process have been combined to develop a specific design for a full scale engine that could be used on the return vehicle of a Mars sample return mission. An engine was then fabricated from this design using a hightemperature superalloy liner supported by a high-strength, lightweight ceramic matrix.

\section{Determination of Engine Thrust Level}

Three recent Mars sample return mission studies were reviewed to determine the appropriate thrust level for a carbon monoxide and oxygen rocket engine. The first study was a 1991 study performed by the Small Mission 
Design Team at the Jet Propulsion Laboratory. ${ }^{10}$ The objective of the study was to outline a smaller (and therefore lower cost) Mars sample return mission, partly through the use of emerging microtechnology. Additional analysis on the baseline mission was performed at the NASA Lewis Research Center in $1993^{11}$ to compare the 1991 baseline with in situ propellant options of either carbon monoxide/oxygen or methane/oxygen. These combined reports will be referred to as the 1991 JPL mission in the rest of this paper.

The second study was based on the work performed at the NASA Johnson Space Center during 1994 and 1995. Their mission was called a Mars sample return mission using in situ resources, or MISR. In order to provide an independent evaluation on the MISR mission, the JSC study team requested a review of their plan by the Advanced Projects Design Team at JPL. ${ }^{12}$ The report from the JPL review was used in this paper for assumptions of dry mass, tankage fraction, and delta velocity mission requirements. This report will be referred to as the JPL Team X mission in the rest of this paper.

The third study was performed in 1995 by Lockheed Martin under contract to NASA JSC. ${ }^{13}$ The objective of this study was to design a Mars sample return mission assuming the production of oxygen and methane on Mars. This report will be referred to as the LM mission in the rest of this paper.

In order to determine the required engine thrust for a carbon monoxide and oxygen ascent vehicle, it was necessary to determine what the three baseline missions would look like if they used $\mathrm{CO} / \mathrm{O}_{2}$ propellants. This analysis was already performed for the $1991 \mathrm{JPL}$ mission. ${ }^{11}$ For the JPL Team X and LM studies, a spreadsheet was prepared based on information provided in the reports. Dry masses were kept constant, and tank masses were calculated as described in the individual reports. Once the spreadsheets were verified by accurately calculating the propellant and vehicle masses of the baseline missions, they were then used to calculate propellant and vehicle masses for an identical mission using carbon monoxide and oxygen.

Table I lists assumed values for mission $\Delta \mathrm{V}$, vehicle dry mass, and initial acceleration for each study. The table also lists the size and number of engines selected for each baseline mission and for each mission assuming carbon monoxide and oxygen propellants. Assumptions for vehicle dry mass will significantly impact the magnitude of the engine thrust. To reduce development costs, it is desirable to use the same engine on both stages, with a single engine on the smaller second stage and multiple engines on the larger first stage. Assumptions for the nesston $\Delta \mathrm{V}$ and initial acceleration will impact whether engine commonality may be maintained.

The required change in vehicle velocity, commonly referred to as delta $\mathrm{V}(\Delta \mathrm{V})$, for a Mars ascent to a direct return to Earth is approximately $6500 \mathrm{~m} / \mathrm{s}$. All three studies assumed a total $\Delta \mathrm{V}$ within 2.5 percent of $6500 \mathrm{~m} / \mathrm{s}$. However, for a two stage vehicle, a decision must be made as to how much $\Delta \mathrm{V}$ will be accomplished by each stage. In this respect, the three studies vary significantly. The 1991 JPL mission assumed nearly a 2 to 1 ratio. The JPL Team $\mathrm{X}$ mission relied on the second stage for the larger portion of mission $\Delta \mathrm{V}$. The LM mission has the delta $\mathrm{V}$ split nearly even between the two stages. In order to maintain engine commonality, an even $\Delta \mathrm{V}$ split or one that requires more $\Delta \mathrm{V}$ from the second stage is desired. $\mathrm{A} \Delta \mathrm{V}$

TABLE I- COMPARISON OF MISSION CRITICAL ELEMENTS FOR BASELINE PROPELLANTS AND CARBON MONOXIDE AND OXYGEN PROPELLANTS

\begin{tabular}{|c|c|c|c|}
\hline $\begin{array}{l}\text { Mission Reference } \\
\text { Mission Element }\end{array}$ & $1991 \mathrm{JPL}$ & JPL Team X & Lockheed-Martin \\
\hline $\begin{array}{l}\text { Stage I } \Delta V(\mathrm{~m} / \mathrm{s}) \\
\text { Stage II } \Delta V(\mathrm{~m} / \mathrm{s}) \\
\text { Total } \Delta V(\mathrm{~m} / \mathrm{s}) \\
\end{array}$ & $\begin{array}{l}4100 \\
2234 \\
6334 \\
\end{array}$ & $\begin{array}{r}2740 \\
3920 \\
\quad 6660 \\
\end{array}$ & $\begin{array}{r}3132 \\
3283 \\
6415 \\
\end{array}$ \\
\hline $\begin{array}{l}\text { Sample return capsule or } \\
\text { earth return vehicle (kg) } \\
\text { Stage II dry mass (w/out tanks) (kg) } \\
\text { Stage II 'final' mass (w/out tanks) }\end{array}$ & $\begin{array}{r}18 \\
35 \\
54\end{array}$ & $\begin{array}{l}20 \\
158 \\
178\end{array}$ & $\begin{array}{l}34 \\
6 \\
40\end{array}$ \\
\hline $\begin{array}{l}\text { Baseline propellants } \\
\text { Stage I initial T/W (mars g) } \\
\text { Stage II initial T/W (mars g) } \\
\text { Baseline engines } \\
\quad \text { Stage I (N (lbf)) } \\
\text { Stage II (N (lbf)) }\end{array}$ & $\begin{array}{c}\mathrm{ClF}_{5} / \mathrm{N}_{2} \mathrm{H}_{4} \\
2.4 \\
2.2 \\
\\
2 @ 2220(500) \\
1 @ 890(200)\end{array}$ & $\begin{array}{c}\mathrm{LOX} / \mathrm{C}_{3} \mathrm{H}_{8} \\
1.2 \\
1.4 \\
\\
3 @ 4450(1000) \\
1 @ 4450(1000)\end{array}$ & $\begin{array}{c}\mathrm{LOX} / \mathrm{CH}_{4} \\
1.8 \\
1.6 \\
\\
4 @ 667(150) \\
1 @ 667(150)\end{array}$ \\
\hline \multicolumn{4}{|c|}{ Baseline missions recalculated assuming $\mathrm{CO} / \mathrm{O}_{2}$ in situ propellants } \\
\hline $\begin{array}{l}\mathrm{CO} / \mathrm{O}_{2} \text { propellants } \\
\text { Stage I initial T/W (mars g) } \\
\text { Stage II initial T/W (mars g) } \\
\mathrm{CO} / \mathrm{O}_{2} \text { engines } \\
\text { Stage I (N (lbf)) } \\
\text { Stage II }(\mathrm{N}(\mathrm{lbf}))\end{array}$ & $\begin{array}{l}4 @ 1334(300) \\
1 @ 1334(300)\end{array}$ & $\begin{array}{l}3 @ 9790(2200) \\
1 @ 9790(2200)\end{array}$ & $\begin{array}{l}3 @ 1334(300) \\
1 @ 1334(300)\end{array}$ \\
\hline
\end{tabular}


split that requires the first stage to deliver much more than the second stage will have the effect of creating a first stage that is much larger than the second stage, and will therefore be difficult to maintain engine commonality, thus increasing engine development costs.

The three studies also varied in dry mass assumptions. Although the masses assumed for the part of the vehicle that actually returned to Earth were similar (from $18 \mathrm{~kg}$ for the $1991 \mathrm{JPL}$ mission to $34 \mathrm{~kg}$ for the LM mission), the JPL Team X mission had significantly larger structural and dry masses for the second stage ascent vehicle. Without the tanks, which were calculated individually, the stage two dry mass was $35 \mathrm{~kg}$ for the $1991 \mathrm{JPL}$ mission, $6 \mathrm{~kg}$ for the LM mission, and $158 \mathrm{~kg}$ for the JPL Team X mission. This significantly larger mass for the second stage dry mass caused all of the previous propellant and vehicle masses to be significantly larger. This in turn will call for significantly larger engines.

The selection of initial acceleration (thrust-to-weight, $\mathrm{T} / \mathrm{W}$ ) for each stage will also affect the size of the engine. On Earth, large, unmanned, launch vehicles begin with a very low acceleration, usually no more than 1.1 times the local gravitational acceleration $(9.8 \mathrm{~m} / \mathrm{s}$ at Earth). This low initial acceleration keeps the engines as small as possible, and also keeps the vehicle speed to a minimum while traveling through the Earth's atmosphere, thereby reducing drag losses. However, the reduction in drag losses are traded with increased gravitational losses. It is this type of trade-off that must also be performed for a Mars ascent vehicle. (The gravitational acceleration for Mars used in this paper is 0.376 times that of Earth, or $3.685 \mathrm{~m} / \mathrm{s}$ ). The three mission studies varied greatly in their selection of initial acceleration. The 1991 JPL study used relatively high T/W for each stage. The JPL Team X mission used lower accelerations more typical of an Earth ascent, and the LM mission used initial accelerations in between the other two missions. One way of maintaining engine commonality between the two stages is by selecting a lower initial acceleration for the first stage and allowing a higher initial acceleration for the second stage.

Table I lists the engine size and number required for the baseline propellants of each mission. Note that the JPL Team X and LM study achieve engine commonality on the two stages, but the 1991 JPL study did not. Engine size for the carbon monoxide and oxygen propellant combination was determined by assuming an initial acceleration between 1.2 and 2.5 local $\mathrm{g}$, and then selecting an engine thrust where three or four engines could be used on the first stage and one engine on the second stage. The LM mission will be used as an example:

$\begin{array}{cc}\text { Stage I initial mass: } & 716 \mathrm{~kg} \\ \text { T/W of 1.2 mars g: } & 3166 \mathrm{~N} \\ \text { T/W of 2.5 mars g: } & 6595 \mathrm{~N}\end{array}$

$\begin{array}{cr}\text { Stage II initial mass: } & 158 \mathrm{~kg} \\ \text { T/W of } 1.2 \text { mars g: } & 699 \mathrm{~N} \\ \text { T/W of } 2.5 \text { mars g: } & 1456 \mathrm{~N}\end{array}$

Assume 3 engines on Stage I:

$3166 / 3=1055 \mathrm{~N}$ minimum

$6596 / 3=2199 \mathrm{~N}$ maximum

Maximum single engine thrust as determined by Stage II: $1456 \mathrm{~N}$

Allowable engine thrust range:

$1055 \mathrm{~N}$ to $1456 \mathrm{~N}$

Using this procedure, the $1991 \mathrm{JPL}$ mission and the LM mission would require $1334 \mathrm{~N}(300 \mathrm{lbf})$ engines. Both would use one of these engines on the second stage. The 1991 JPL mission would use 4 engines on the first stage, and the LM mission would use 3 engines on the first stage. The JPL Team X mission has much larger thrust requirements caused by the higher dry masses assumed. This mission would require a $9790 \mathrm{~N}$ (2200 lbf) engine, using 3 on the first stage and one on the second stage. It should be noted that the baseline missions also had selected engines with significantly different thrusts, ranging from $667 \mathrm{~N}(150 \mathrm{lbf})$ in the LM study to $4450 \mathrm{~N}(1000 \mathrm{lbf})$ in the JPL Team X study. Therefore, a "full-scale" carbon monoxide/oxygen engine for a Mars sample return mission was designed for an ideal thrust of $2225 \mathrm{~N}$ (500 lbf). Although this thrust level does not match any of the specific missions studied, it is representative of engine size and is appropriate to demonstrate performance.

\section{Determination of Engine Geometry}

Initial ignition tests performed in a spark torch igniter ${ }^{5}$ indicated that the carbon monoxide and oxygen combination was difficult to ignite without a catalyst present. However, with only $0.3 \mathrm{wt} \%$ hydrogen added to the carbon monoxide, ignition and sustained combustion was achieved. This was the first indication that the known slow kinetics of this propellant combination would require special attention.

Theoretical analysis and experimental results of subscale combustion tests ${ }^{6}$ further raised the issue of slow kinetic reactions. In this case, the high combustion gas temperatures $(\sim 3280 \mathrm{~K})$ appeared to cause significant dissociation in the chamber, while the slow kinetics hampered the recombination that would normally occur in the chamber and nozzle. This combination of high dissociation and slow recombination was theorized to be the reason for the measured specific impulse efficiencies of only 86 to 88 percent.

Experiments with carbon monoxide and oxygen in a calorimeter chamber ${ }^{7}$ also indicated that slow kinetics 
may need to be considered when determining the proper combustion chamber length. Results indicated that the peak heat flux of the gaseous propellants occurred as far as $7 \mathrm{~cm}$ (2.75 in.) downstream of the injector. In addition, the chamber heat flux did not level out until the end of the $14.9 \mathrm{~cm}$ (5.9 in.) chamber, indicating that combustion continued throughout the chamber. The measured combustion efficiencies of 96 percent indicated relatively complete combustion by this point. Additional length, however, will be required for liquid propellants to allow time for vaporization.

Using the knowledge gained from these experimental tests of carbon monoxide and oxygen, an analytical computer program for liquid propellant performance (LPP) was used to determine an optimum geometry. ${ }^{14}$ This computer program uses a chamber and nozzle geometry together with thermodynamics and kinetics to predict the performance that an actual engine will experience in normal operation. The code consists of several modules, each of which models a different type of performance loss. These modules are One-Dimensional Equilibrium(ODE), One-Dimensional Kinetics (OYKK), Two-Dimensional Kinetics (TDK), and Mass Addition Boundary Layer (MABL). All modules assume complete combustion in the chamber, that is, no loss in energy release due to slow vaporization or nonuniform mixing.

\section{Mixture Ratio}

The ODE module was used to calculate vacuum specific impulse. A chamber pressure of $3450 \mathrm{kPa}$ ( 500 psia) was selected as an upper limit for a pressure fed engine for a space mission. Because tank pressure is usually 1.5 times chamber pressure or higher, any additional increase in chamber pressure will cause tank mass to increase to an unacceptable level. An expansion ratio of 200 to 1 was selected as a compromise between engine performance and nozzle weight. Figure 1 shows the variation in vacuum specific impulse with mixture ratio $(\mathrm{O} / \mathrm{F})$ for liquid carbon monoxide and liquid oxygen. The stoichiometric mixture ratio for these propellants is 0.571 . Optimum specific impulse occurs slightly below stoichiometric, at a mixture ratio of 0.55 . This mixture ratio was used for all subsequent engine design and analysis.

\section{Throat Area}

The throat area was determined from the selected thrust level and chamber pressure, and the thrust coefficient calculated from the ODE module. For a selected thrust level of $2225 \mathrm{~N}$ ( $500 \mathrm{lbf}$ ), a chamber pressure of $3450 \mathrm{kPa}$ ( $500 \mathrm{psia}$ ), and a mixture ratio of 0.55 , the vacuum thrust coefficient is 2.171. The throat area and radius are therefore:

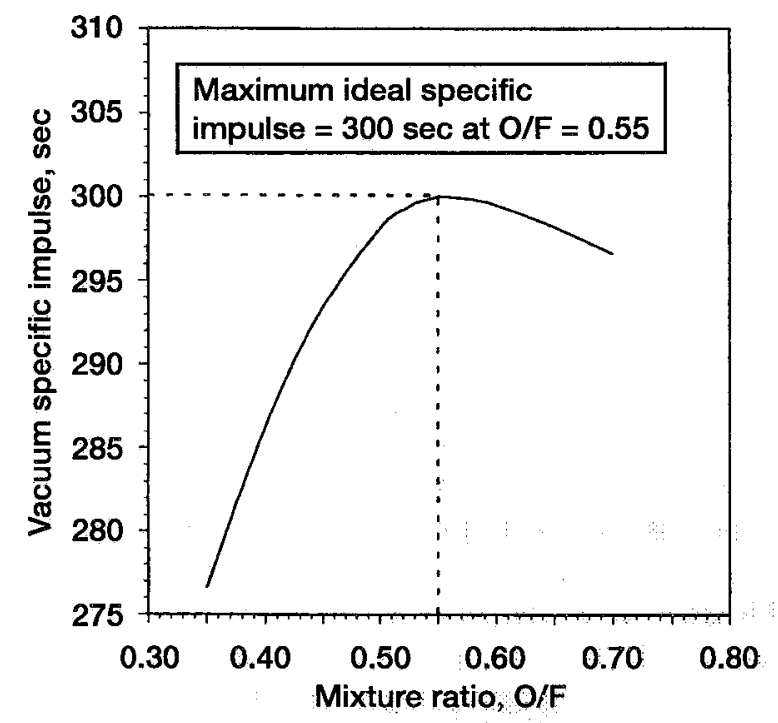

Figure 1.-Theoretical vacuum specific impusse of liquid oxygen/liquid carbon monoxoce, assuming one dimensional equilibrium, $3450 \mathrm{kPa}$ (500 psia) chamber pressure, and expansion area ratio of 200.

$$
\begin{gathered}
A_{t}=\frac{(2.225 \mathrm{~N})(100 \mathrm{~cm} / \mathrm{m})^{2}}{(3450 \mathrm{kPa})(2.171)}=2.971 \mathrm{~cm}^{2} \\
R_{t}=\sqrt{\frac{2.971 \mathrm{~cm}^{2}}{\pi}}=0.972 \mathrm{~cm}(0.383 \mathrm{in})
\end{gathered}
$$

Although the one dimensional equilibrium assumptions used to determine thrust coefficient and therefore throat radius are ideal predictions, this throat radius was used for further engine design.

\section{Parametric Analysis of Nozzle Geometry}

For all modules of the LPP computer program except for ODE, a full engine and nozzle geometry needs to be described before calculations can be made. Figure 2 illustrates a general engine geometry, and labels the various parts that must be specified. ${ }^{15}$ Table II lists the parts of the engine geometry, the values selected for the baseline engine, and the range of values evaluated during the parametric analysis. All radii are nondimensionalized by the throat radius. Once values were selected for the above variables, the nozzle was determined by a computer program $^{16}$ that calculates an optimum nozzle contour using the optimization method that was developed by Rao. ${ }^{17}$ This nozzle contour was then used as input for the LPP engine performance program. 


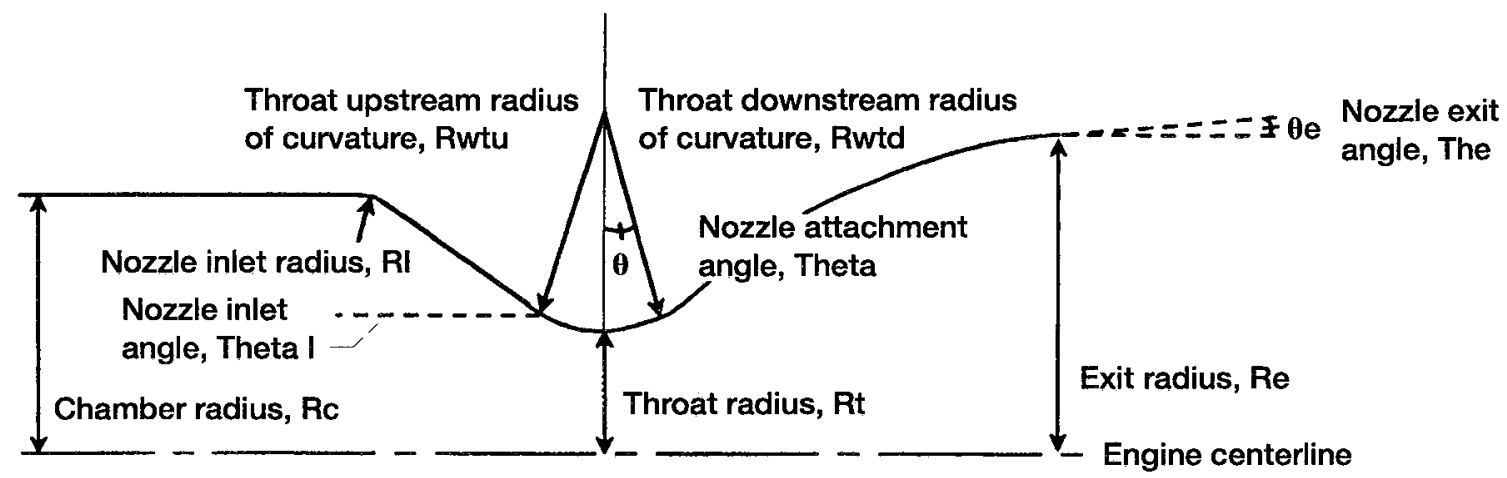

Figure 2.-Generalized engine geometry, with critical parameters labelled.

TABLE II.-DESCRIPTIVE ELEMENTS OF ENGINE GEOMETRY AND BASELINE VALUES

\begin{tabular}{|c|c|c|c|}
\hline Element & Description & Baseline value & $\begin{array}{l}\text { Range evaluated } \\
\text { in parametrics }\end{array}$ \\
\hline CTrat & $\begin{array}{l}\text { Contraction ratio: ratio of chamber } \\
\text { area to throat area }\end{array}$ & 4.0 & 2.0 to 6.0 \\
\hline RI & $\begin{array}{l}\text { Nozzle inlet radius: radius of arc at } \\
\text { transition point between chamber } \\
\text { and converging nozzle }\end{array}$ & 0.05 & 0.05 to 0.25 \\
\hline ThetaI & $\begin{array}{l}\text { Nozzle inlet angle: angle of } \\
\text { converging nozzle }\end{array}$ & $25^{\circ}$ & $20^{\circ}$ to $35^{\circ}$ \\
\hline Rwtu & $\begin{array}{l}\text { Upstream throat radius of curvature: } \\
\text { curved section leading up to throat }\end{array}$ & 2.0 & 1 to 10 \\
\hline Rwtd & $\begin{array}{l}\text { Downstream throat radius of } \\
\text { curvature: curved section } \\
\text { immediately after throat }\end{array}$ & 2.0 & 1 to 10 \\
\hline Theta & $\begin{array}{l}\text { Nozzle attachment angle: angle at } \\
\text { tangent point where arc described by } \\
\text { Rwtd ends and optimum nozzle } \\
\text { begins }\end{array}$ & $\begin{array}{l}\text { Determined by } \\
\text { optimum } \\
\text { nozzle program }\end{array}$ & $\begin{array}{l}5^{\circ} \text { to } 10^{\circ} \\
\text { for cone options }\end{array}$ \\
\hline EPS & $\begin{array}{l}\text { Nozzle expansion ratio: ratio of } \\
\text { nozzle exit area to throat area }\end{array}$ & 200 & 200 \\
\hline
\end{tabular}

In order to evaluate various engine geometries, the onedimensional kinetics (ODK) module of the LPP program was used. Because most of the losses are driven by kinetics, this module was sufficient to compare initial performances while being efficient to use. The effects of the engine geometry on the kinetics were determined by examining the mass fractions of the species present in the chamber and nozzle. Figure 3(a) and (b) shows the carbon monoxide, oxygen, and carbon dioxide mass fractions as predicted by the ODE and the ODK modules. The equilibrium module predicts that there is significant recombination of the carbon monoxide and oxygen between the throat and an expansion area ratio of $\sim 4$ or 5 . This can be seen by the decreasing concentrations of the carbon monoxide and oxygen in Fig. 3(a), and the simultaneous increase in concentration of carbon dioxide in Fig. 3(b). The ODK module, however, predicts very little recombination past the throat.

Figure 4 shows the combustion gas temperature from the throat to an expansion area ratio of 5 . It can be seen in the figure that both the equilibrium and the kinetics modules predict a sharp decline in temperature, with the kinetics prediction more severe than the equilibrium. As the gases expand in the diverging nozzle, their temperature cools rapidly. By comparing Figs. 3 and 4, it can be seen that both modules agree that chemical reactions only occur while the gas temperature remains above $\sim 2600 \mathrm{~K}$. The ODK module predicts that the temperature reaches $2600 \mathrm{~K}$ by an area ratio of 2 , while the ODE module does not predict $2600 \mathrm{~K}$ until an area ratio of 5 . Because the gases have more time to continue their reactions before the temperature becomes too cold, the ODE module predicts more recombination. Therefore, in an effort to maintain higher temperatures in the near-throat region, the engine geometry was varied parametrically to determine which parameters had the greatest effect on combustion gas temperature.

The nozzle geometry parameters were varied one at a time, and the ODK predicted $\mathrm{CO}_{2}$ mass fraction and vacuum specific impulse were studied as indicators of a 


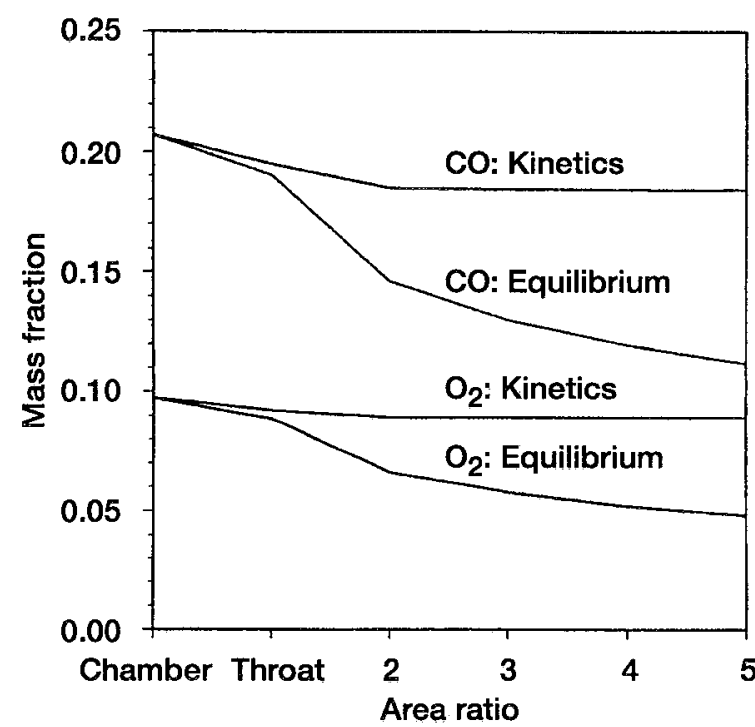

Figure 3a.-Comparison of theoretical mass fractions of carbon monoxide and oxygen as predicted by equilibrium and kinetics assumptions.

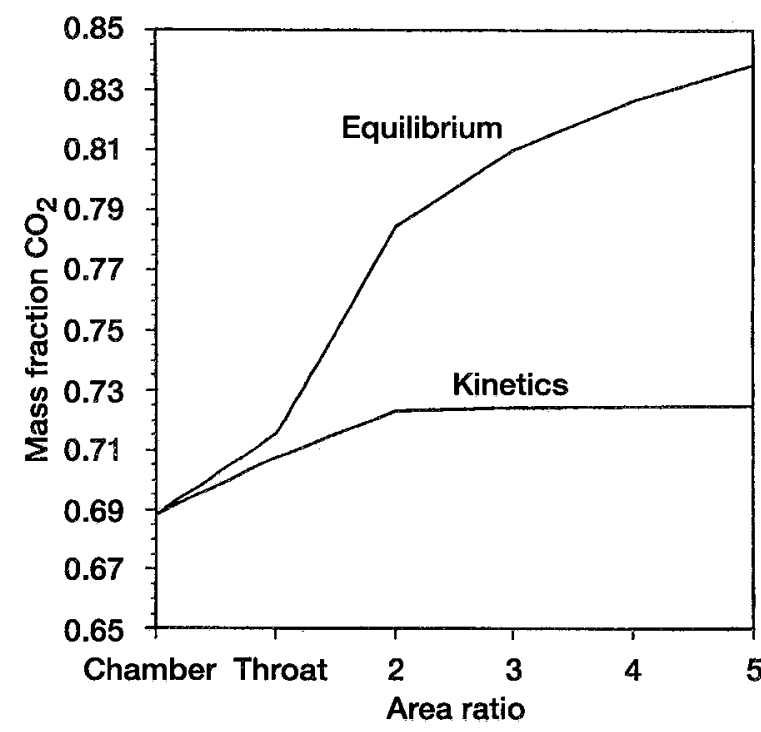

Figure 3b.-Comparison of mass fraction of carbon dioxide as predicted by equilibrium and kinetics assumptions.

more optimum value. Contraction ratio, nozzle inlet radius, nozzle inlet angle, upstream throat radius, and downstream throat radius were varied as shown in Table II. Although some minor fluctuations were observed, the only variable that had any substantial effect on the performance was the downstream nozzle throat radius.

Figure 5 shows the carbon dioxide mass fraction for increasing downstream nozzle throat radius. The figure shows that as Rwtd increases from 1 to 10 , the $\mathrm{CO}_{2}$ mass

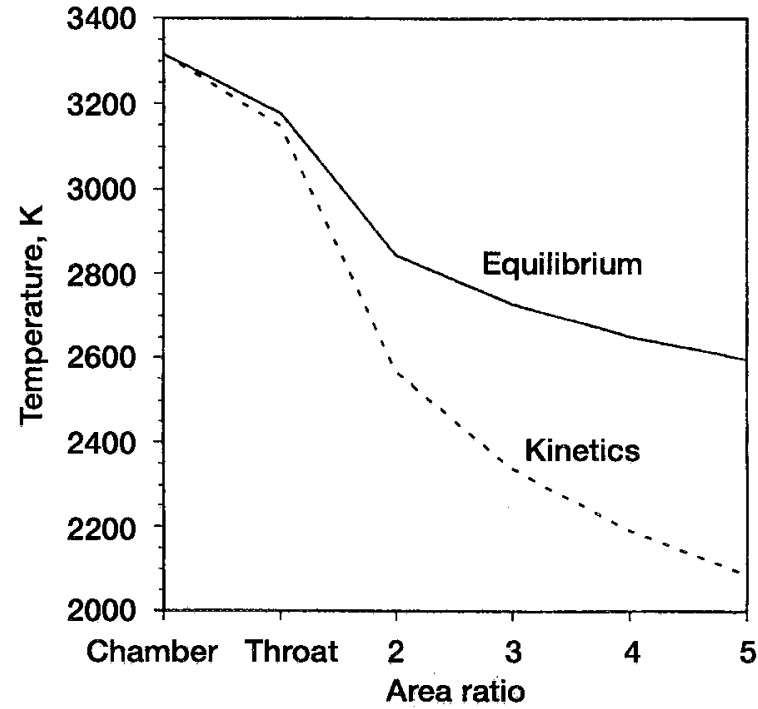

Figure 4.-Comparison of gas temperatures for carbon monoxide and oxygen combustion as predicted by equilibrium and kinetics assumptions.

fraction increases from 0.724 to 0.736 . This is sufficient for an increase in specific impulse from 277.2 to $279.0 \mathrm{sec}$. A larger downstream nozzle throat radius provides for a slower expansion of the gases, which therefore allows for more time for recombination before the temperature becomes too cold. This result suggested that a nontraditional type of nozzle geometry may provide for even better performance.

A new nozzle geometry was developed where the downstream throat arc transitions into a shallow cone instead of directly into a bell nozzle. Once the cone reaches an expansion area ratio of 4 , an optimum Rao nozzle is added. Figure 6 shows the resulting increase in carbon dioxide mass fraction. The new cone and bell geometry further increases the $\mathrm{CO}_{2}$ mass fraction to 0.754 . This new geometry provides an ODK specific impulse of $281.6 \mathrm{sec}$. The original baseline geometry, the optimized geometry with a full bell nozzle, and the final geometry with a cone transition to a bell, are shown to scale in Fig. 7. A cylindrical chamber length of $20.3 \mathrm{~cm}$ (8 in.) was selected to allow sufficient time for vaporization and combustion.

These three geometries were then run through the complete engine prediction code, including the twodimensional kinetics and the boundary layer modules. The results raised additional issues with the cone/bell geometry. Because the cone expands so slowly for the first 4 area ratios, the nozzle was extended 1 inch over the other geometries to allow sufficient time for a smooth expansion out to an area ratio of 200 . Even with the additional length, the exit angle is larger than the optimum bell geometry, $8.8^{\circ}$ compared to $6.8^{\circ}$. This causes larger divergence 


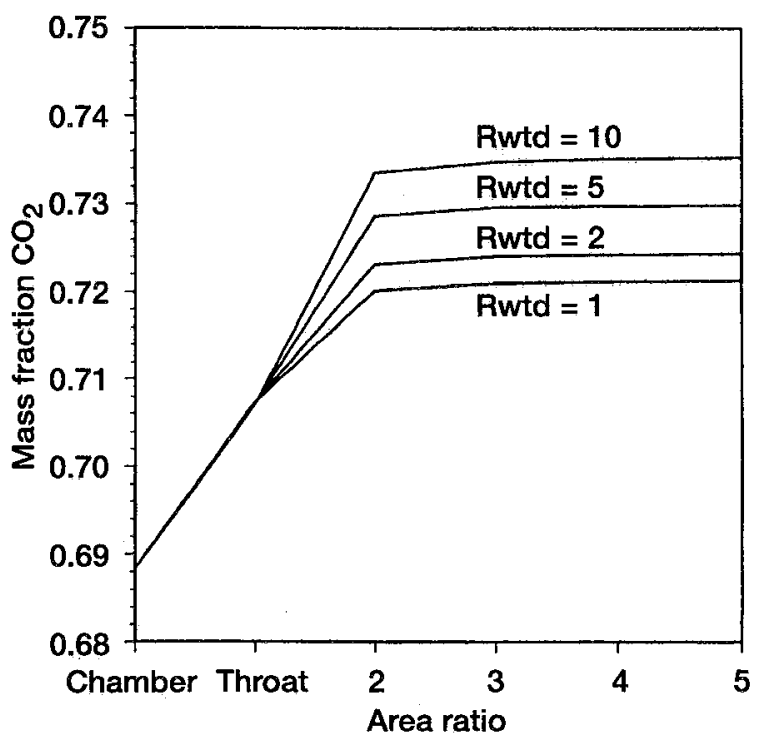

Figure 5.-Effects of increasing downstream throat radius on carbon dioxide mass fraction.

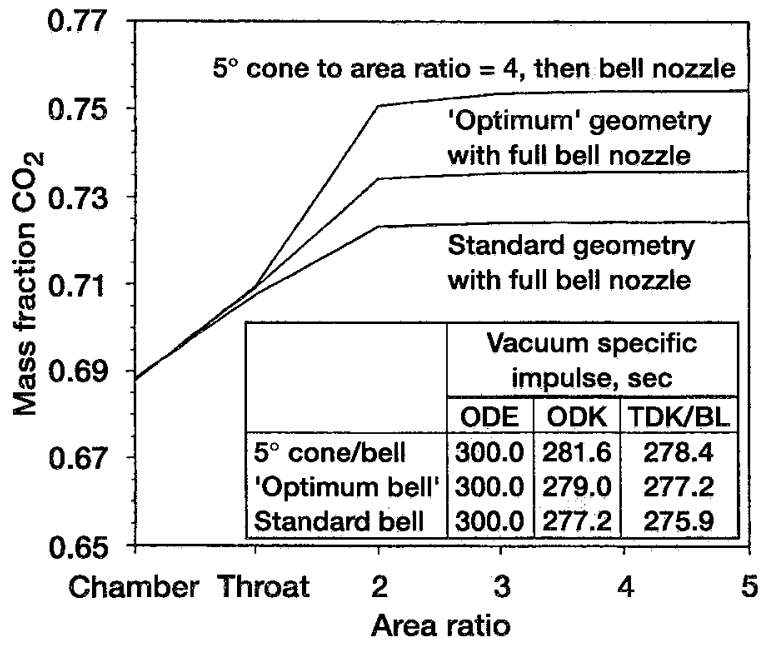

Figure 6.-Comparison of optimum bell nozzle with nozzle that begins with a $5^{\circ}$ cone.

losses in the cone/bell nozzle. The specific impulse predicted by the TDK/BL modules, also listed in Fig. 6, is $278.4 \mathrm{sec}$ for the cone/bell nozzle and $277.2 \mathrm{sec}$ for the optimum bell nozzle.

\section{Full Scale Mars Sample Return Prototype Engine}

The results of the parametric analysis were used to design an engine for a Mars sample return mission. The cone/bell geometry was selected for this engine. Because the engine is to be tested at Earth sea level conditions, the engine was built only to an expansion area ratio of 5 to prevent overexpansion of the gases. The cone shape was maintained for the entire length. The ideal vacuum thrust

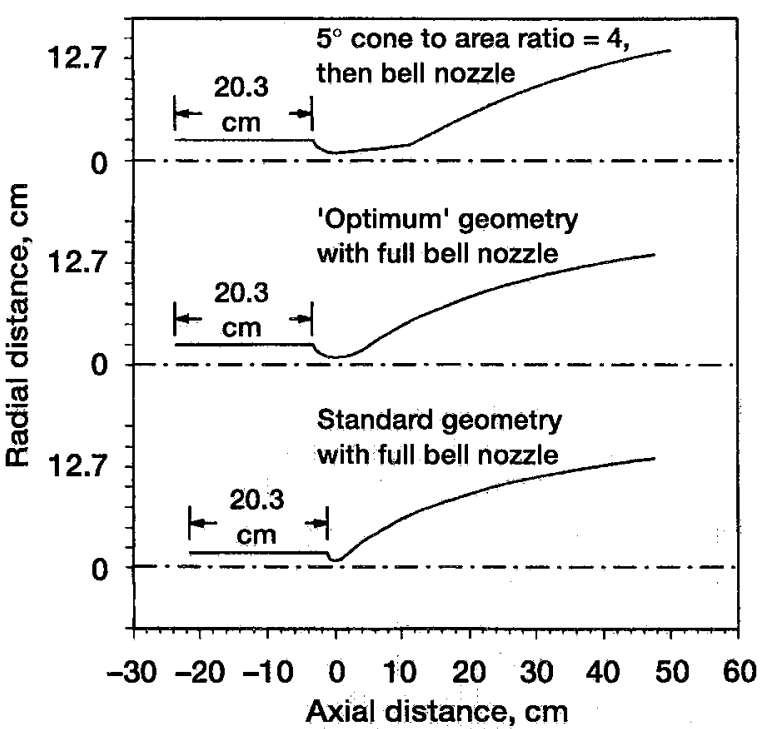

Figure 7.-Graphical representation of the baseline, optimum bell, and cone-with-bell engine geometries, assuming a $20.3 \mathrm{~cm}$ (8 inch) combustion chamber.

of the full cone/bell nozzle with a 200 to 1 expansion ratio is $2225 \mathrm{~N}$ (500 lbf). The TDK/BL prediction for thrust is $2060 \mathrm{~N}$ (463 lbf). Assuming a combustion chamber efficiency of 97 percent, delivered thrust is predicted to be $2000 \mathrm{~N}$ (450 lbf). Experimental testing of this engine will provide the data required to verify the predictions of the LPP computer program, and allow a flight engine to be designed to deliver the thrust that is selected for the mission.

\section{Prototype Mars Engine}

During a Mars sample return mission, the engine will sit dormant for a great length of time while travelling through space and while in the dusty surface environment of Mars. Because the use of turbomachinery would be risky in this environment, a pressure-fed engine will most likely be used. A pressure-fed engine, however, cannot use active regenerative cooling of the combustion chamber and nozzle without driving tank pressure up to an unacceptable level for a planetary mission. In addition, the pressure-fed engine will deliver slightly lower specific impulse performance because of its lower operating pressure.

\section{Engine Materials}

The challenge, then, is to develop a method to keep the engine cool without violating other mission requirements of high performance and low mass. Fuel film cooling is one method of maintaining the chamber walls at an acceptable temperature, but this will reduce the specific 
impulse by purposely creating inefficient mixing. Similarly, high-temperature refractory metals have been used on small engines to attain full performance with passive cooling. ${ }^{18}$ Such engines, however, quickly become very heavy as engine thrust level is increased. For the carbon monoxide/oxygen Mars engine, it was decided to investigate a combination of high-temperature materials for the combustion chamber and nozzle liner, and lightweight materials to provide the bulk strength.

Refractory metals such as iridium and rhenium can operate continuously at temperatures up to $\sim 2200{ }^{\circ} \mathrm{C}$. Because rhenium is susceptible to oxidation, a thin coating of iridium is generally used with the rhenium to protect the rhenium from excessive oxidation. The oxidation rate of iridium, however, begins to increase above about $2000^{\circ} \mathrm{C}$ at a rate of 10 times per every $100^{\circ} \mathrm{C} .{ }^{19}$ Hafnium oxide can also be added to the inner diameter of the iridium to provide additional gas diffusion and thermal barrier. It is estimated that a liner composed of $\mathrm{HfO}_{2} /$ Ir/Re (from the inside working out) can be operated at temperatures up to $2400^{\circ} \mathrm{C}$ continuously.

The major drawback of using rhenium for the entire engine is its density of $21 \mathrm{gm} / \mathrm{cm}^{3}$. For this reason, light- weight, high-strength ceramics were considered for the structural strength of the engine. Carbon-carbon (C-C) has a density of only $1.6 \mathrm{gm} / \mathrm{cm}^{3}$, and can operate continuously at temperatures up to $1700^{\circ} \mathrm{C}$. Attempts in the past to add high-temperature metal liners to ceramic engines, however, have had problems in maintaining the bond between the metals and the ceramic because of the large difference in the coefficients of thermal expansion.

\section{Fabrication Methods}

For this engine, a different manufacturing method was employed in which a mandrel was first formed with outer dimensions equal to the inner dimensions of txe engine. The engine was then constructed in an inside-out manner. First, the hafnium oxide was plasma sprayed onto the mandrel. Then the iridium and rhenium were put down using CVD. Finally, the carbon-carbon was applied. The mandrel was then slowly removed using chemical etching. It is anticipated that during engine operation, the iridium-rhenium liner will actually expand into the carboncarbon shell, thus providing excellent bonding and support.

A thin niobium sleeve was added to the first two inches of the combustion chamber, over the carbon-carbon,

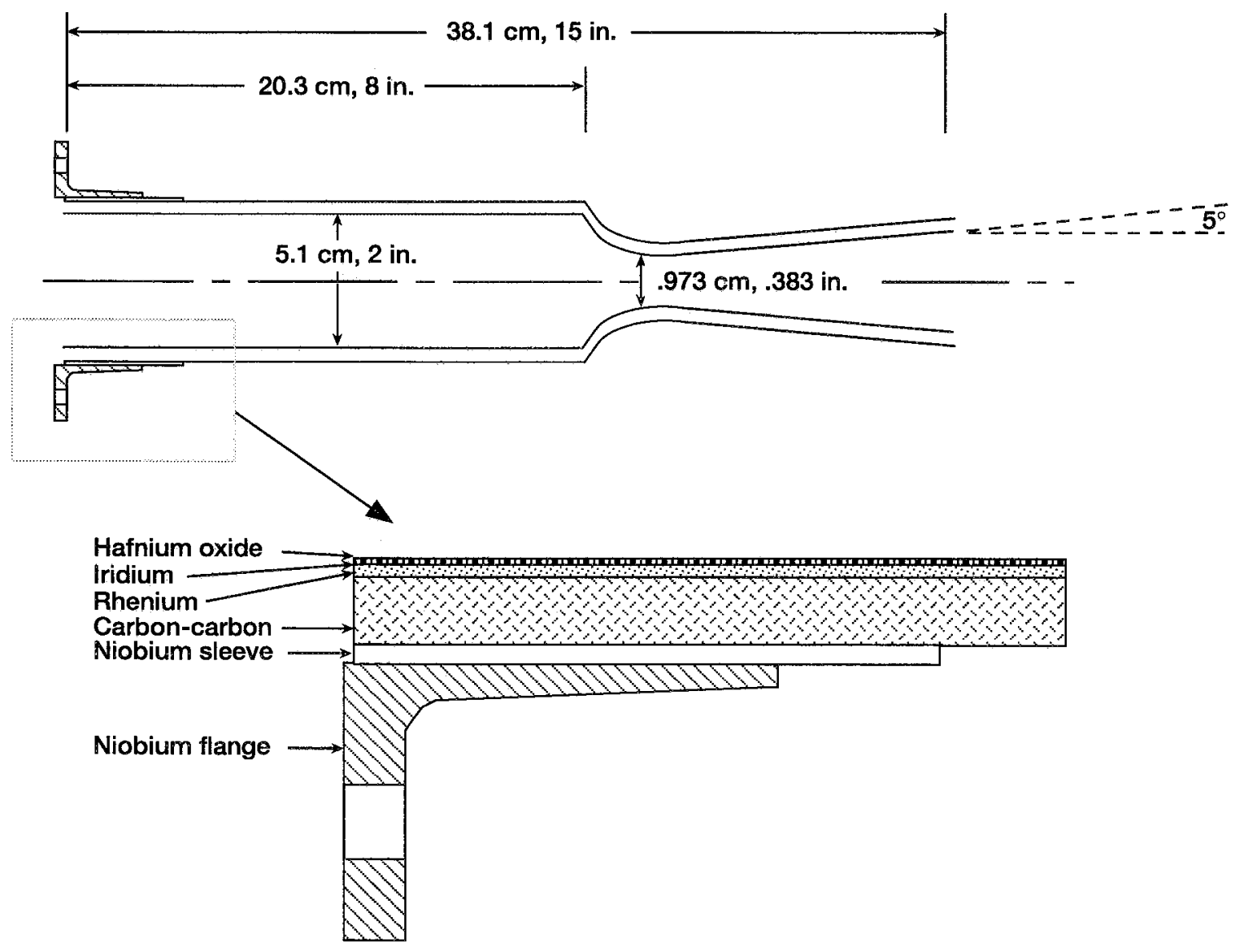

Figure 8.-Earth sea level engine showing dimensions and materials. 
TABLE III.-MATERIALS AND OPERATING TEMPERATURES OF MARS

\begin{tabular}{|l|l|c|c|}
\hline \multicolumn{1}{|c|}{ Material } & \multicolumn{1}{|c|}{ Function } & $\begin{array}{c}\text { Maximum } \\
\text { operating } \\
\text { temperature, } \\
{ }^{\circ} \mathrm{C}\end{array}$ & $\begin{array}{c}\text { Design } \\
\text { thickness, } \\
\mathrm{cm}\end{array}$ \\
\hline Hafnium oxide & Secondary gas diffusion barrier & 2400 & 0.0127 \\
\hline Iridium & Primary oxidation barrier & $2200-2400$ & 0.0051 \\
\hline Rhenium & Primary thermal barrier & 2200 & 0.1016 \\
\hline Carbon-Carbon & Structural strength & 1700 & 0.635 \\
\hline
\end{tabular}

using CVD. A niobium flange was then welded to this sleeve to provide an attachment mechanism for the injector face. Figure 8 shows a schematic of the engine and flange, and details the layers of the engine. Table III summarizes each material, its purpose, temperature, and the design thickness for the Mars sample return engine. Figure 9 shows a picture of the engine.

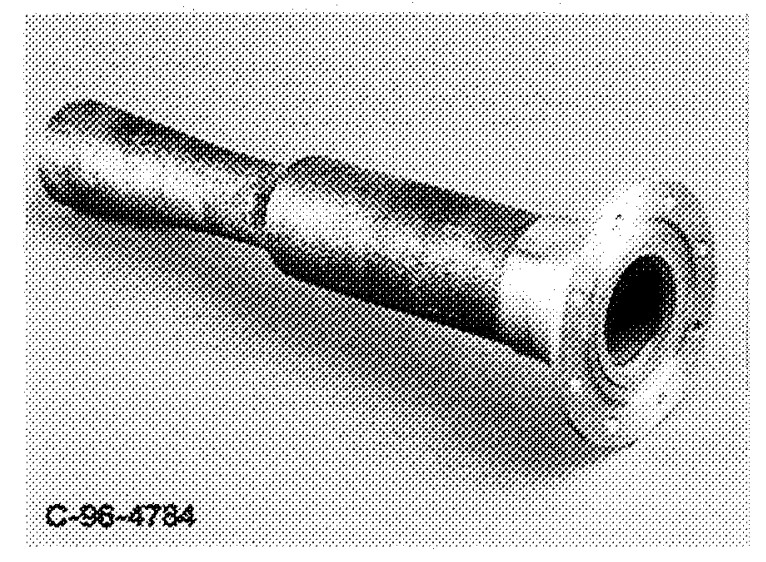

Figure 9.-Protype Mars engine, with truncated nozzle.

\section{Concluding Remarks}

A Mars sample return mission is currently scheduled for launch in 2005. Innovative technologies such as in situ propellants and lightweight engines can help maintain mission launch costs within the target level of a Delta IIIclass launch vehicle. The propellant performance and materials need to be tested at full scale to demonstrate technology readiness for the mission.

Current mission designs indicate that an engine between 667 and $4450 \mathrm{~N}$ (150 and $1000 \mathrm{lbf}$ ) will be needed for the Mars ascent vehicle. Therefore, an engine that should deliver $2000 \mathrm{~N}$ (450 lbf) at Mars sea level with carbon monoxide and oxygen propellants has been designed using analytical and experimental experience. This engine design, with a short nozzle for an Earth sea level test, has been built using a unique combination of high-temperature refractory metals and lightweight ceramic composites. A test of this engine on a thrust stand for a duration of $\mathrm{omin}$ will demonstrate that carbon monoxide: and oxygen propellants, and lightweight engine materials, are ready for a Mars sample return mission.

\section{Acknowledgment}

The parametric engine analysis was based in part on extensive parametric analyses performed by $\mathrm{Mr}$. Ron Bates, July, 1993.

\section{References}

1. Stancati, M.L., Niehoff, J.C., Wells, W.C., Feingold, H., and Ash, R.L., "In Situ Propellant Production for Improved Sample Return Mission Performance," AAS 79-177, 1979.

2. French, J.R., "Rocket Propellants from Martian Resources,' Journal of the British Interplanetary Society, Vol. 42, pp. 167-70, 1989.

3. Zubrin, R.M., Baker, D.A., and Gwynne, O., "Mars Direct: A Coherent Architecture for the Space Exploration Initiative," AIAA 91-2333, June, 1991.

4. Giudici, B., "A Get Started Approach for Resource Processing," AAS 87-262, in The Case For Mars III: Strategies for Exploration-Technical, July, 1987.

5. Linne, D.L., Roncace, J., and Groth, M.F., "Mars In Situ Propellants: Carbon Monoxide and Oxygen Ignition Experiments," AIAA 90-1894, NASA TM-103202, July, 1990.

6. Linne, D.L., "Carbon Monoxide and Oxygen Combustion Experiments: A Demonstration of Mars In Situ Propellants," AIAA 91-2443, NASA TM-104473, June, 1991.

7. Linne, D.L. "Performance and Heat Transfer Characteristics of a Carbon Monoxide/Oxygen Rocket Engine," NASA TM-105897, February, 1993.

8. Linne, D.L., "Experimental Evaluation of the Ignition Process of Carbon Monoxide and Oxygen in a Rocket Engine," AIAA 96-2943, NASA TM-107267, July, 1996. 
9. Williams, B.E., and Tuffias, R.H., "Small Composite Combustion Chambers," Final Report (ULT/TR93-6392), NASA Contract NAS9-18840, July, 1993.

10. Jet Propulsion Laboratory, "Concepts for a Small Mars Sample Return Mission Using Microtechnology," JPL D-8822, October, 1991.

11. Wadel, M.F., "Benefits of In Situ Propellant Utilization for a Mars Sample Return Mission," AIAA 93-2244, NASA TM-106243, June, 1993.

12. Kaplan, D., Private Communication, NASA Johnson Space Center, Houston, TX, October, 1996.

13. Lockheed Martin, "Mars Sample Return Mission Utilizing In Situ Propellant Production," Final Report, NAS9-19359, March, 1995.

14. Nickerson, G.R., Berker, D.R., Coats, D.E., and Dunn, S.S., "Two-Dimensional Kinetics (TDK) Nozzle Performance Computer Program," NAS839048, March, 1993.
15. Huzel, D.K., and Huang, D.H., "Design of Liquid Propellant Rocket Engines," second edition, NASA SP-125, 1971.

16. Nickerson, G.R., Dang, A.L., and Dunn, S.S., "The Rao Method Optimum Nozzle Contour Program," NAS8-36863, February, 1988.

17. Rao, G.V.R., "Exhaust Nozzle Contour for Optimum Thrust," Jet Propulsion, Vol. 28, June, 1958.

18. Reed, B.D., "Long Life Testing of Oxide-Coated Iridium/Rhenium Rockets," NASA TM-107054 (also AIAA 95-2401), July, 1995.

19. Tuffias, R.H., Williams, B.E., andFortini, A.J.,"NextGeneration Rhenium-Based Thrust Chambers. presented at 7th AeroMat Conference, June, 1996. 

Public reporting burden for this collection of information is estimated to average 1 hour per response, including the time for reviewing instructions, searching existing data sources, gathering and maintaining the data needed, and completing and reviewing the collection of information. Send comments regarding this burden estimate or any other aspect of this collection of information, including suggestions for reducing this burden, to Washington Headquarters Services, Directorate for information Operations and Reports, 1215 Jefferson Davis Highway, Suite 1204, Arlington, VA 22202-4302, and to the Office of Management and Budget, Paperwork Reduction Project (0704-0188), Washington, DC 20503.

\begin{tabular}{|l|l|l|}
\hline 1. AGENCY USE ONLY (Leave blank) & $\begin{array}{c}\text { 2. REPORT DATE } \\
\text { January } 1997\end{array}$ & $\begin{array}{r}\text { 3. REPORT TYPE AND DATES COVERED } \\
\text { Technical Memorandum }\end{array}$ \\
\hline
\end{tabular}

4. TITLE AND SUBTITLE

5. FUNDING NUMBERS

A Rocket Engine for Mars Sample Return Using In Situ Propellants

6. AUTHOR(S)

Diane L. Linne

7. PERFORMING ORGANIZATION NAME(S) AND ADDRESS(ES)

8. PERFORMING ORGANIZATION REPORT NUMBER

National Aeronautics and Space Administration

Lewis Research Center

Cleveland, Ohio 44135-3191

E-10601

9. SPONSORING/MONITORING AGENCY NAME(S) AND ADDRESS(ES)

10. SPONSORINA/MONITORING AGENCY REPORT NUMBER

National Aeronautics and Space Administration

Washington, DC 20546-0001

NASA TM-107396

AIAA-97-0893

\section{SUPPLEMENTARY NOTES}

Prepared for the 35th Aerospace Sciences Meeting \& Exhibit sponsored by the American Institute of Aeronautics and Astronautics, Reno, Nevada, January 6-10, 1997. Responsible person, Diane L. Linne, organization code 5830, (216) 977-7512.

12a. DISTRIBUTION/AVAILABILITY STATEMENT

12b. DISTRIBUTION CODE

Unclassified -Unlimited

Subject Categories 20 and 28

This publication is available from the NASA Center for AeroSpace Information, (301) 621-0390.

13. ABSTRACT (Maximum 200 words)

Recent studies for the planned Mars sample return mission were reviewed and modified to utilize carbon monoxide and oxygen as potential in situ propellants. Based on these studies a representative full scale engine thrust of $2225 \mathrm{~N}$ (500 lbf) was selected as appropriate to demonstrate performance, and the design for that engine is presented. Previous experimental results combined with parametric analyses were used to define the geometry for the engine which operates on liquid carbon monoxide and liquid oxygen. The engine was constructed using a combination of high-temperature alloys and lightweight ceramics. The materials selected were hafnium oxide, iridium, rhenium, and carbon-carbon.

14. SUBJECT TERMS

15. NUMBER OF PAGES

12

Carbon monoxide; Mars; Extraterrestrial resources; Rocket engine design

17. SECURITY CLASSIFICATION OF REPORT

Unclassified

\author{
18. SECURITY CLASSIFICATION \\ OF THIS PAGE \\ Unclassified
}

19. SECURITY CLASSIFICATION OF ABSTRACT Unclassified
16. PRICE CODE

A03

20. LIMITATION OF ABSTRACT

Standard Form 298 (Rev. 2-89) Prescribed by ANSI Std. Z39-18 298-102 
National Aeronautics and

Space Administration

\section{Lewis Research Center}

21000 Brookpark Rd.

Cleveland, $\mathrm{OH}$ 44135-3191

Official Business

Penalty for Privale Use $\$ 300$

POSTMASTER: If Undeliverable - Do Not Return 